\title{
USE OF INTRAVENOUS LIDOCAINE IN THE TREATMENT OF COMPLEX REGIONAL PAIN SYNDROME TYPE II: A CASE REPORT
}

\author{
Melo e Assis W, Conceição VM, Costa Filho MM, Modesto MM, Santana TB
}

\section{BACKGROUND}

Neuropathic pain (NP) is a result of an injury or disease that directly affects the somatosensitive system. The Complex Regional Pain Syndrome (CRPS), among NPs, represents a distinct entity with sympathetically mediated pain. Among the drugs available for treatment, lidocaine has been used in several ways, including intravenously. This study reported the use of intravenous lidocaine in the treatment of a patient with CRPS type II and low adherence to pharmacological treatment.

\section{CASE REPORT}

A 32-year-old chronic pain patient, female, with lumbar disc herniation L4-L5 e L5-SI, submitted to an arthrodesis. Without improvement of the algic symptoms, was submitted to a new surgical procedure associated to the sciatic nerve block in orthopedic service. Postoperative, the symptoms got worse, with significant impairment of daily activities, including loss of work capacity. In the Chronic Pain Sector of the Hospital das Clínicas da Fundação Hospital do Acre, the patient classified her pain as DN4 $=6$, S-LANSS $=24 E V A=10$ and the diagnosis of definitive neuropathic pain with autonomic phenomena was confirmed. Clinical treatment was initiated with low doses of Nortriptyline and Pregabalin with slight improvement of the autonomic symptoms. After 120 days of oral treatment, lidocaine intravenous $2 \mathrm{mg} / \mathrm{kg}$ in continuous infusion pump for 60 minutes and weekly intervals was associated.

\section{DISCUSSION}

The use of lidocaine in CRPS was reported as benefic for some patients. The patient in question obtained a satisfactory result in the control of the symptoms and significant improvement of the quality of life with return to work and to the practice of physical activity. After the 8th dose her pain was classified as EVA $=2$, DN4 $=4$ and S-LANSS $=3$, and these scores were maintained a year after the intravenous treatment, proving a prolonged analgesia.

\section{LEARNING POINTS}

(I) Although the half-life of the lidocaine is only 120 minutes, analgesia provided by systemic lidocaine is prolonged and may extend for days or even weeks.

(2) The dose varies between I to $5 \mathrm{mg} / \mathrm{kg}$ administered over a period of 30 to 60 minutes in weekly intervals.

(3) There is no literature report on the number of applications required per treatment. In practice, the solution is used until the pain scores decrease.

REFERENCES: (I) Souza MF, Kraychete DC. A ação analgésica da lidocaína intravenosa no tratamento da dor crônica: uma revisão de literatura. Revista brasileira de reumatologia. 2014; 54(5):386-392. 